\title{
DESCRIPTIONS OF LARVAE AND PUPAE OF TWO- WINGED FLIES BELONGING TO THE FAMILY LEPTIDAE
}

\section{By Charles T. Greene}

Of the Bureau of Entomology, United States Department of Agriculture

This paper contains descriptions of 7 species of larvae and 11 species of pupae of flies belonging to the dipterous family Leptidae. It is based on a study of the material representing larvae and pupae of this family in the collections of the United States National Museum, supplemented by certain specimens which have kindly been lent to me by C. W. Johnson, of the Boston Society of Natural History. The specimens used in this paper are labeled with the number herein given to the species and with a reference to the number of this article.

Various authors have divided the group as here treated into three families-Leptidae, Xylophagidae, and Coenomyidae-but after a careful study of the immature stages I am convinced that they represent only one family group, and to this the name Leptidae should be applied. In my studies of the immature stages of Diptera I have found that the form of the spiracle in the pupa is constant for each family. Should this group be divisible into three families one would expect to find three distinct forms of spiracles, but in the material available only one type occurs, which very strongly confirms my impression that these insects do not belong to more than one family.

The adults of the family Leptidae vary in size from small to large and robust species. Their flight is rather slow, and the majority of them are found flying about foliage along the edge of woods and shady places. Some few species, however, are frequently found resting on tree trunks or old logs. The species of the genera Rhachicerus, Xylomyia, and Xylophagus very closely resemble certain ichneumon flies belonging to the order Hymenoptera. None of the adults of this family are injurious to man, although many species of the genus Symphoromyia are annoying, because they persistently fly about the heads of men and animals, and one or two species have been reported as actually sucking the blood. The habits of the larvae are varied. Many are predacious and some are scavengers. 
A brief summary of the habits of the larvae of each species is given under the species. The larvae show many more variations in form and structure than do the pupae, and I think that this is probably explained by their adaptation to the more various ecological situations.

The principal character used in the description of the larvae and pupae is the spiracular plate, and from an examination of all the material before me this seems to be a very constant character. The spiracular plates in all of the species, except that belonging to the genus Vermiteo, are very similar, and in all the spiracular entrance, or so-called spiracular opening, closely resembles the script capital letter "E." There is, however, sufficient variation in the location, form, and size of the spiracles to offer very useful diagnostic characters.

Some of the principal characters used are the following:

Spiracular entrance (pl. 2, fig. $9 r$ ).-This term means the main spiracular opening which contains numerous small openings called the slits.

Peritreme (pl. 2, fig. 9q).-By this term is here meant chitinous ridge or elevation which directly limits the spiracular entrance.

Basal.-This term means the end of the abdominal segment toward the thorax.

The material available make it possible to prepare the following family diagnosis :

Larva.-Generally cylindrical, smooth, white to pale yellow and with or without prolegs; head pointed and heavily chitinized or only partially chitinized; posterior spiracles located on the surface and no posterior cavity. Or the larva is depressed, gray-brown in color, the entire surface covered with scale-like plates; posterior spiracles in a cavity which opens transversely but generally is closed and forms a linear depression.

Pupa.-Typically orthorrhaphous in form with the antennal capsules large and located on the anterior edge of the head; these capsules are free from the head on their apical half or more. Or the antennal capsules may be small, slightly raised on the surface of the head, giving to the head the appearance of being bent downward. The spiracular plates closely resemble each other but vary in size from quite small to large.

LARVAE

TABLE OF SPECIES

1. Larva entirely chitinized and slightly flattened; surface reticulate.

(No. 1) Xylomyia pallipes Loew.

Larva not as above

2. Head elongated, pointed, heavily chitinized

Head not as above 
3. Chitin on the dorsum of the first segment shaped like small amoebae.

(No. 2) Rhachicerus nitidus Johnson.

Chitin on the dorsum punctate

4. Chitin on the first two segments only; posterior spiracles elliptical in shape as in figure $3 h_{--}$

Chitin on the first three segments; posterior spiracles oval in shape as in figure $4 j$

(No. 4) Xylophagus abdominalis Loew.

5. Larva with prolegs on all the abdominal segments; two plumose caudal appendages (No. 5) Atherix variegata Walker.

Larva not as above

6. With several large bristles near the caudal end which have hooks at the apex; head capsule large_-_-_-(No.6) Vermileo comstockii Wheeler. Not as above but with four lobes at the caudal end.

(No. 7 ) Chrysopila, species. ${ }^{1}$

PUPAE

TABLE OF SPECIES

1. Outer puparium shaped like the larva; transparent pupal skin always protruding from the dorsal exit hole_--- (No. 1) Xylomyia pallipes Loew.

Puparium not shaped like the larva

2. From a dorsal view, the antennal capsules are at the anterior end of the head.

From a dorsal view, the antennal capsules are below the anterior end of the head.

3. With processes at the antero-basal portion of the antennal capsules--- 4

Without antennal processes; antennal capsules free; a circlet of long hairs on the dorsal side of the eye; spiracles as in figure $S$.

(No. 8) Xylophagus abdominalis Loew.

4. Antennal processes pointed and directed outward; spiracles as in figure 9 (No. 9) Xylophagus lugens Loew.

Antennal processes flattened and directed forward, inner apical points touching; spiracles with bead-like slits as in figure 10 .

(No. 10) Rhachicerus nitidus Johnson.

5. Head small; abdomen tapering posteriorly to a point; spiracles very small; anterior thoracic spiracle with a large spine below; abdominal spiracles reniform with four radiating pale lines, see figure 11.

(No. 11) Vermileo comstockii Wheeler.

Head large; sides of abdomen nearly parallel_____________-__-_ 6

6. Anterior portion of head with a very large rugose prominence; puparium very large and robust; spiracles as in figure 12.

(No. 12) Coenomyia ferruginea Scopoli.

Head without the prominence.

7. Spiracles located on large flattened chitinous plates as in figure 13 .

(No. 13) Leptis mystacea Macquart.

Spiracles not on a flattened plate

8. Spiracles quite small; slits arranged in pairs with light-colored spaces between as in figure 14 - (No. 14) Chrysopila quadrata Say.

Spiracles larger and more normal in size

9. Spiracular plate rounded_-__- 10

Spiracular plate elongate elliptical as in figure $\mathbf{1 5 .}$

(No. 15) Chrysopila fasciata Say.

${ }_{1}^{1}$ This species is either Chrysopila ornata or thoracica. 
10. Spiracular plate quite large as in figure 16; puparium with two small bristles in the middle of the thoracic dorsum.

(No. 16) Chrysopila foeda Loew. Spiracular plate smaller, of medium size, as in figure 17 ; puparium with four small bristles in the middle of the thoracic dorsum.

(No. 17) Chrysopila ornata Say.

\section{DESCRIPTIONS OF SPECIES}

XYLOMYIA PALLIPES Loew

Plate 1

Habits.-Larvae are usually scavengers and may occasionally be predacious. They have been found under the bark of fallen cottonwood trees (Poputus) and also under the bark, and in the fermenting sap in wounds, of tulip poplar (Liriodendron).

Larva (fig. 1).-Small; dull, dark yellowish brown; head pointed; body transversely elliptical; sides parallel; 11 segments, in addition to the head, of nearly equal length; the last segment slightly longer and rounded apically; surface of body reticulate except for a large bare area on the dorsum of the first segment and a smaller area on the second; dorsal anterior surface of head terminates anteriorly into a sharp process; on the side of the head, below the apex, is the minute two-jointed thimble like antenna with the apical joint much smaller; near the basal outer angle of head is a small yellow bristle; near each dorso-anterior angle of segments 2 to 10 is a depression; segments 4 to 11 have a transverse, anterior row of small, round depressions, those of the last segment are larger; segment 1 has two bristles at each anterior corner; segments from 1 to 10 have a dorsal pair of bristles just back of the transverse middle line and the segments from 2 to 11 have one lateral bristle; at each posterior angle of the last segment is a small bristle; on the venter, all segments except the last have a pair of widely separated bristles; along the ventral segmental line of the last segment are four bristles, the two middle ones the smaller; just back of the middle is a transverse row of four bristles, between this row and the apex of the segment are two bristles; anal opening surrounded by a rounded ridge. Anterior spiracle (fig. $a$ ) on the side of the first segment; it is heavily chitinized, dark yellowish red, the anterior end much darker; the narrow, distinctly elevated ridges are pale yellow. The posterior end of the larva opens transversely like a mouth, and within the lips, which are yellowish brown chitinized, smooth and shining, is a central depressed plate with a rounded ridge around the edge; in the middle of this plate is a rounded elongate elevation with six small, rounded punctures on each side, in the upper part are two transverse rows of small, rounded punctures and at each of its lower corners are situated 
the posterior spiracles (fig. $b$ ) ; these spiracles are yellowish brown, nearly circular, with a broad flat peritreme which is divided into about 32 equal parts, nearly rectangular and separated from each other by very fine grooves; inside of the peritreme is a large depressed area with a roughly granular surface and in the center of this depression is a dark brown, small, smooth, circular area.

Length, $9 \mathrm{~mm}$.; width, $2 \mathrm{~mm}$.; thickness, $1.4 \mathrm{~mm}$.

Arlington Farm, Va. Larvae and pupae from Robinia podagrica, reared March 12, 1906, by A. D. Hopkins. Hopk. U. S. No. 6062.

Pupa (fig. 1).-Very thin, shining, transparent, with a yellowish tinge. Antennal capsules large, pointing outward, faintly annulated to the tip; just posterior to the base of these are three faint ocellar punctures. Thorax slightly longer than wide, smooth; wing pads smooth, reaching to the apex of the third abdominal segment; thoracic spiracle (fig. $c$ ) situated on a small elevation; the spiracular entrance is golden yellow, sinuous, and contains a great number of short radiating slits. Abdomen cylindrical, composed of eight segments; first and last segment without any spines; segments 2 to 7 with a transverse, dorsal row of reddish yellow spines just posterior to the middle of the segment; segments 1 to 7 have a spiracle (fig. $d$ ) on the antero-lateral surface; spiracle small, golden yellow, slightly elevated; last segment rounded at apex and entirely smooth.

Length, $6 \mathrm{~mm}$.; diameter of thorax, $1.85 \mathrm{~mm}$.; diameter of abdomen, $1.75 \mathrm{~mm}$.

\section{RHACHICERUS NITIDUS Johnson 2}

Plates 1 and 2

Habits.-Larvae are predacious, and were found in the decayed trunks of sycamore trees which were lying on the ground.

Larva (fig. 2).-Small, ivory white, cylindrical; head elongated, pointed, dark yellowish red, heavily chitinized, with three pairs of bristles, one pair near the apex, one pair near the middle, and one pair near the base; there are 11 segments in addition to the head; segments from 1 to 5 short and of equal length; segments 6 to 11 a little longer than the preceding segments and of equal length; encircling each segmental line is a row of small, round yellow spots. Anterior spiracle (fig. $e$ ) is located posteriorly on the side of the first segment; it is nearly elliptical, reddish yellow, and around the edge shining; the middle is depressed and granular, and at the anterior end of the depression are six small elongated tubercles pointing backward. On the dorsum of segment 1 is a small triangle

2 It is of interest to notice the difference in the texture of the chitin in the closely allied genrea Rhaohicerus and Xylophagus. 
of reddish yellow chitin which is composed of small amoebalike pieces. Caudal plate is reddish yellow, large, nearly round and terminating in a broad bifid projection with two pointed prongs, which are well separated and curved upward; each prong has three bristles; on the ventral side at the base of this caudal projection is a pair of large bristles; in the middle of the caudal plate is a faint depression in which are several small, rounded punctures and a row of four similar punctures on each side; near the base of the plate are the posterior spiracles (fig. $f$ ) ; they are round, slightly elongate, and darker red, with the middle part faintly depressed and surrounded by a narrow, serrated, light-colored band; in the center of the depression is a small black crescent band; anterior to the spiracles is a pair of bristles and on each side are two bristles. Venter of first segment has on each side a triangle of chitin like that on the dorsum; between segments 3 and 4 , and between all of the following segments to between 9 and 10 , is a roughened transverse band of small reddish spines. Anal opening elongate, surrounded by a narrow darkened linear depression which has a V-shaped arm on each side.

Length, $9 \mathrm{~mm}$.; diameter, $1.4 \mathrm{~mm}$.

Rosslyn, Va., April 25, 1913, in rotton log, R. C. Shannon, collector. Great Falls, Va., April 12, 1924, larvae in log of sycamore, pupated May 11, 1924, adults emerged May 25, 1924, C. T. Greene, collector.

Pupa (fig. 10).-Pale to dark reddish yellow; nearly opaque; head and thorax more shining than the abdomen, which is cylindrical and rather dull. The antennal capsules are more reddish than the head, annulated and enlarged at bases; a deep rugose depression occurs between the bases of the antennal capsules; a small yellow bristle directed forward is situated near the anterior portion of each of them, and on their anterior edge is a large keel-shaped, rugose, inwardly directed projection, both projections touching each other, and generally there is an opening between them, but sometimes not; head is rounded and bears three deep, circular, ocellar punctures; on the side of each posterior ocellus is a small bristle-like hair. Thorax much longer than wide; near the anterior dorsal end is a sinuous row of small rounded punctures which are much larger laterally; at the anterior angles of the thorax are the prothoracic spiracles (fig. s) which are of a very deep reddish color; the slits in the entrance place are rounded, bead-like, and pale yellow. The abdomen is composed of eight segments, the first segment about half as long as the second and the segments from 2 to 7 about equal in length; dorsum of segment 1 has a transverse row of four pairs of bristles near the transverse median line, and segments from 2 to 7 have two 
transverse widely separated rows of spines; in the posterior row the spines are larger and some have a hair-like termination; each segment from 1 to 7 has a small spiracle (fig. $t$ ) which in color and shape looks like the thoracic one (fig. $s$ ), and below each spiracle is a spine; last segment is rounded posteriorly and has a tail-like prolongation; anteriorly, there is a transverse row of four widely separated, long, pointed spines terminating like a hair; at the middle is a transverse, granular, dull area, and posteriorly it ends with a pair of broad, bifid lobes; each lobe is compressed, rounded dorsally, but ventrally sharp and spine-like; ventrally and near the base the segment bears two widely separated pairs of small spines. Leg capsules reach to the first fifth of the second segment.

Length, 8-10 mm.; width of thorax, 1.5-2 mm.

\section{XYLOPHAGUS LUGENS Loew}

Plates 1 and 2

Habits.-Larvae are predacious on beetle larvae and were found under the bark of chestnut, pine, and oak.

Larva (fig. 3).-Very much like Xylophagus abdominalis with the following exceptions: The anterior portion of the head has a single bristle on each side; posterior to this bristle are two others closely set together and at the base is a single bristle; the chitinous plates on the dorsum are absent on segment 3 ; on the anterior edge of the chitin of the first segment is only a single bristle on each side; anterior spiracle (fig. $g$ ) is deep red with the anterior portion rounded and the posterior terminating in a long, narrow band; the anterior portion has a transverse, reddish yellow, crescent-shaped area divided into narrow parallel structures, which are pointed anteriorly, and in front of this area is a narrow, black, curved band; just back of the reddish yellow crescent-shaped area is a narrow, light-colored, spindle-shaped one inclosed by a darker ring. Caudal plate bifid at apex with the two prongs widely separated at the base; posterior spiracle (fig. $h$ ) is elliptical, slightly elevated, very dark red, and apparently open in the center; the design following the contour is arranged as a double row of short serrat lines. Ventral sides of segments 1 and 2 either entirely covered or nearly covered with chitin; anal plate almost circular and the roughened border around this plate and the $\mathrm{V}$-shaped arms on each side are very wide.

Length, 15-19 mm.; diameter, 2-2.75 $\mathrm{mm}$.

Great Falls, Va.; larvae under bark of chestnut feeding on larvae of Urographis fasciata (Degeer). Larvae collected March 28, 1917; adults emerged April 2, 1917, C. T. Greene, collector. Virginia shore, near Plummer Island; no date; H. S. Barber, collector. Dead 
Run, Fairfax County, Va., March 20, 1924. Adults emerged March 24, 1924, C. T. Greene, collector.

Pupa (fig. 9).--Light amber yellow; semitransparent; thorax more shining than the abdomen; abdomen nearly cylindrical. The antennal capsule is annulated and more reddish yellow than the head; on the upper edge of the base of the capsule and pointing outward is a hornlike, cylindrical projection, and at the base is one large bristlelike hair; between the bases is a deep groove, and apically on the head is a small plate with four rounded punctures; head capsule smooth with the ocellar depressions well defined; immediately in front of the sinuate posterior suture, and on each side of the median line, is a transverse row of eight or nine slightly elongate depressions or punctures. Thorax nearly as wide as long; just back of the middle of the lateral margin is a large single bristle; at the anterior portion, on the dorsum, are four rounded depressions, and just back of these is a transverse, slightly arcuate row of similar depressions; on each dorsal anterior angle of the thorax is located a thoracic spiracle (fig. $q$ ) ; these spiracles are slightly more reddish than thorax and have a raised black ridge; upon the latter is located the spiracular entrance, which contains a series of small radiating slits arranged in a sinuous line. The abdomen is composed of eight segments; the first segment is rather narrow; the third to eighth of nearly equal length; segments from 1 to 7 have a spiracle (fig. $r$ ), which is very similar to the thoracic spiracle but smaller, and with the ridge more brown than black; below each abdominal spiracle is a spinelike bristle; first segment has a transverse row of four long: bristles on its dorsal and more numerous bristles on its lateral portions, while the segments from 2 to $\tau$ have a transverse row of closely set laterally longer bristles, and on these latter segments a broad, transverse, rugose band is present along the basal margin; last segment is longer but not so wide as the preceding; it bears a transverse enlargement along which are large bristly spines arranged in groups of four; and it terminates in a large prolongation which apically is split into two conical lobes, each with a blackish point; the ventral sides of the segments from 1 to 7 bear a transverse row of bristles corresponding to those on the dorsal sides; the last segment has two spinelike outward-pointing projections on the renter, near the middle. Leg capsules reach the middle of the third segment.

Length, 11-14 mm.; width of thorax, 2-3 mm.

\section{XYLOPHAGUS ABDOMINALIS Loew}

Plates 1 and 2

Habits.-Larvae are predacious on beetle larvae which were found under the bark of pine. 
Larva (fig. 4).-Large, elongate, cylindrical, ivory white; head black, pointed and chitinized when fully extended longer than shown in figure 4 ; on the antero-dorsal portion are two parallel punctures; near the anterior end of each of these punctures is a pair of short bristles; farther back is another pair of bristles; just posterior to this pair and nearer the median line is a single bristle; on the side, near the base, is a single bristle. There are 11 segments in addition to the head; the first longer than the second; second segment rather short; segments 3 and 4 of equal length, a little longer than the second; segments 5 to "10 much longer than segment 4, and each succeeding segment slightly longer than the preceding; first three segments with deep reddish, mahogany-colored chitin plates on the dorsum; chitin plates on the third segment vary from two large spots, as shown, to a continuous band; anterior spiracle (fig. i) large, chitinized, mahogany red, broadly rounded anteriorly and tapering to a point at the posterior end; in the broad portion is a transverse elliptical blackish area with a round black dot in the middle; in front of this is a broad crescent-shaped yellowish area with a middle row of bead-like tubercles, and anterior to this area is a narrow, black, crescent-shaped band; the segments from 4 to 9 have a transverse, antero-dorsal band of red chitinous spines; first segment has three large bristles dorsally on side; segments 2 and 3 have two bristles, dorsally, on each side; segments 4 to 10 have two bristles laterally on each side; segments 1 to 10 have a single bristle on the lateral surface near the middle; the last segment has three bristles on each side, and a heavily chitinized plate is present at its apex, anterior edge of plate pointed, and posterior end of plate bifid, each prong curving outward; on the dorsum of this plate are present on each side, one large bristle in the middle; two similar ones laterally, one at the base of the prong and two near its apex; on the ventral surface is a single bristle; on the dorsum of the plate, near the base of the prongs, on each side is located the posterior spiracle (fig. $j$ ) ; this is very dark red; the middle portion is depressed and has a large dark spot at the anterior end, and around the middle depressed area is an elevated, flattened ridge divided into 62 small rectangular plates; on each side of the middle part of the dorsum of the last segment is a large irregular, chitinous plate, and along the anterior segmental line on each side are two smaller, irregular plates of red chitin which are variable in size. On the ventral surface each segment from 1 to 3 has a pair of widely separated bristles near the transverse middle line of the segment; the venter of segment 1 has red chitin along the anteroir edge extending along the lateral edges until it reaches the posterior end of the segment, and on the segments from 4 to 10 is a transverse, roughened band of small chitinous points present anteriorly; anal 
opening long, in the center of a large, broad, oval-shaped area which has a $V$-shaped arm on each side; the edge of this oval-shaped area and the arms are roughened; each segmental line is completely encircled by a row of small, chitinous, rounded dots.

Length, 25-28 mm.; diameter, $2.75-3 \mathrm{~mm}$.

Riverton, N. J., larvae and pupae under damp bark of pine March 20. Male and female adults emerged April 5, C. W. Johnson, collector. Falls Church, Va., October 10, 1913, C. T. Greene, collector. Webster, N. H., reared May 4, 1906, W. F. Fisk, collector. Hopks. U. S. No. 3731f. Falls Church, Va., reared June 12, 1916, from under bark of Pinus virginiana by C. T. Greene.

Pupa (fig. 8).-Light amber yellow; semitransparent, with the thorax shining and the abdomen rather dull and cylindrical. The antennal capsule annulated, more reddish yellow in color; there is a deep groove between the bases of the antennal capsules; no hornlike projection at base of capsule; at the dorsal base of each antenna is one long yellowish, bristle-like hair; the plate or area back of the antennae has two raised parts on each side; three ocellar punctures present; to the outer side of these punctures, on each side, is a group of about 15 long yellow bristle-like hairs; postero-dorsal suture of the head is sinuous and marked by about a score of elongated, narrow depressions. The thorax is much longer than wide; near the anterior end of dorsum is a transversely arcuate row of punctures, which are larger toward the middle of the row, and near its posterior end is a sinuous suture with numerous elongated narrow punctures in front; the anterior or prothoracic spiracle (fig. o) is deep reddish yellow with several wrinkles which are much darker in color, and it is located at the outer anterior angle of the thorax; spiracular slits light yellow, radiating and arranged in a sinuous row whose ends are bent toward each other and nearly touching; on each side of the thorax, near the transverse middle line, is a large bristle-like hair; just back of this hair and above it are two similar hairs: near the posterior end of thorax is a sinuous suture having numerous, elongated, narrow punctures along its anterior edge; and near the posterior angles of the thorax, on each side, are two bristles. Abdomen cylindrical or occasionally depressed, composed of eight nearly equally long segments; segments from 1 to 7 , on each side, with a shining reddish yellow spiracle (fig. $p$.) similar in color to the prothoracic; below each abdominal spiracle is a spinelike bristle; first segment with a transverse row of widely separated bristles along the posterior edge; these bristles are more numerous toward the lateral end; posterior margin of segments 2 to 7 with a row of closely set bristles which are longer laterally; each of the segments fram 2 to 7 , when fully extended, has a broad transverse 
rugose band along the basal margin; last segment swollen laterally, with four pairs of bristles arranged in a transverse row across the middle of the dorsum; apex bilobed, each lobe rounded apically and terminating with a large bristle; ventrally, the posterior margins of segments from 1 to 7 are provided with a transverse row of bristles in continuation of the dorsal rows, and medianly on the ventral side of the last segment are two small tubercles which terminate in a laterally projecting spine.

Length, 12-15 mm.; width of thorax, $2.25-3 \mathrm{~mm}$.

\section{ATHERIX VARIEGATA Walker}

\section{Plate 1}

Habits.-The eggs are deposited in dense masses attached to dry branches overhanging water. Numerous females contribute to the formation of these egg masses and they also remain there and die. The larvae hatching drop into the water, where they are predacious.

Larva (fig. 5).-Large, luteous, cylindrical, smooth; 11 segments; first four segments tapering anteriorly; the caudal segment with two long processes; prolegs well developed. Both thoracic and abdominal spiracular plates undeveloped. Head quite small, well developed, retractile; antenna small, cylindrical, pointed, about four times longer than its diameter. Segments 1 to 3 have three large bristly hairs on each side, arranged in a vertical row; segment 4 has a small, pointed tubercle on the latero-dorsal portion, and one pair of well developed prolegs (fig. k) with large, hook-like spines on their ventral surfaces; posterior to each proleg are two spine-like hairs; segments 5 to 10 similar to the fourth but larger, the tubercles are larger and there is an additional pointed process on the lower anterior part of the side; this process is much longer on the tenth segment; last segment slightly smaller than the preceding segment and has two pointed, plumose processes which are slightly longer than the segment; on the side of the segment is a horizontal row of long, delicate yellow hairs; anal opening on the dorsum between the bases of the two processes; on the dorsum, on each side, is a group of three long bristly hairs, and on the venter is a single median proleg; posterior to this and above it is a transverse, elliptical, smooth, white respiratory organ, which can be inflated. On the ventral surface of each of the abdominal segments from 1 to 7 and posterior to the prolegs, is a pair of bristle-like hairs; at the ventral base of each caudal process there is also a bristle-like hair.

Length, $18 \mathrm{~mm}$.; diameter, $2.25 \mathrm{~mm}$.

Beltsville, Md., in Paint Branch, July 2, 1922, H. S. Barber, collector. 


\section{VERMILEO COMSTOCKII Wheeler}

Plates 1 and 2

Habits.-The eggs are deposited in sand, and the larvae form conical pitfalls in which to ensnare small insects.

Larva.-The dried larval skin is opaque white and is so distorted that it is impossible to give any idea of the shape. It is fastened at the tip of the pupa (fig. 11) ; near the caudal end of the larva, and apparently on the dorsum, are three pairs of very stout yellowish spines which taper to a hook-like point; the mouth parts (fig. 6) are deep brown, semitransparent; head capsule seen from above pyriform in outline, the anterior portion irregularly sculptured; in the lateral view it is arched dorsally; the long central rod is broad and arched; the small rods at the anterior end are parallel to the main rod.

Even after soaking this larval skin for a day or two I was unable to add anything to the above.

Pupa (fig. 11).-Medium sized, semitransparent, very faintly yellowish white, thorax semitransparent with a yellowish brown infuscation and slightly larger in diameter than the abdomen; abdomen tapering slightly toward the apex. Head small, rounded; antennal capsules elongated, pointed and slightly raised from the undersurface of the head. Thorax longer than broad and smooth; wing pads with numerous short rugosities; on the dorso-lateral surface of the thorax, near the anterior end, is located the thoracic spiracle (fig. $u$ ); this spiracle is very small, deep brownish black, shining, with the narrow outer edge and the central design paler in color; directly below the spiracle, directed forward and slightly downward, is a long, tapering, spine-like bristle. Abdomen is composed of eight segments of about equal length but tapering toward the apex; on the intersegmental skin are two transverse lines composed of very small, roughened areas which may be easily concealed in the segmental folds; near the antero-lateral angle of the segments from 1 to 7 , are the abdominal spiracles (fig. $v$ ), which are very small, reniform, with an anterior concavity, and brownish black with four radiating, narrow, dark yellow stripes. The last segment is very narrow but otherwise can not be described on account of the larval skin being attached in such a way that it can not be removed.

Length, $8 \mathrm{~mm}$.; diameter of thorax, $1.75 \mathrm{~mm}$.; diameter of abdomen at base, $1.25 \mathrm{~mm}$.

Larval skin attached to apex of puparium. Alta Meadows, Calif., no date, Dr. W. M. Wheeler, collector. 


\section{CHRYSOPILA, species}

Plate 1

Habits.-Larvae appear to be scavengers. They are found under dead leaves on the ground in the woods and also in the wet frass in tree holes.

Larva (fig. 7).-Large, white, cylindrical, elongate, smooth; first two segments tapering slightly to the small head; 11 segments in addition to the head. Head (fig. l) small, its dorsal portion with faintly impressed lines, giving the surface a slightly rugose appearance; the frontal portion of the head $(f p h)$ is heavily chitinized, the chitin is reddish yellow, and is divided into a right and left half, each half terminating in an arcuate row of large, elongated teeth; seen from above, the head is divided antero-medianly by an elongate, keel-shaped plate $(p l)$ which is compressed below; on each side of this plate is an elongated, triangular area, covered with reddish yellow spines pointing upward and slightly backward; laterally, is a small oval elevation upon which is located the antenna; this is white, cylindrical, single jointed, slightly larger at the base and with its length about five times its diameter; mandibles $(m d)$ triangular, robust, heavily chitinized, reddish-yellow ; maxillary palpus white, smooth, cylindrical, its length about four times its diameter. On each side of the ventral surface of the head are two small bristles. First 10 segments are of equal length; the integument along each segmental line is raised into 5 to 7 transverse rows of slightly flattened ridges and each ridge is divided into short scale-like parts of unequal length. Anterior spiracle (fig. $m$ ) small, slightly elevated, yellow, located on the side of the first segment, oval in outline; the center with a small, circular white spot, and two small oval depressions posterior to this spot; last segment slightly rounded, terminating in four pointed, flattened lobes, the under surface of which is yellowish and slightly rugose; these lobes have a short yellow fringe of hairs around the edge, and each lobes has a large bristle in the middle of its inner face just before the apex; between the upper and lower lobes is a large conical tubercle pointing backward; on the side of last segment are several well defined, linear depressions; anal opening in the middle of the venter of last segment, located on a large, rounded, rugose elevation. Posterior spiracle (fig. $n$ ) is situated at the base of each upper lobe; it is heavily chitinized, reddish yellow, and in outline elliptical with a slight dorsal concavity; the peritreme is divided into 40 equal parts which are pointed distally, and proximally at their bases is a row of short, radiating, raised lines; in the center of the spiracle is a transverse, sinuous depression. 
Length, $26 \mathrm{~mm}$.; diameter, $3 \mathrm{~mm}$.

Near Plummer Island, Md., March 20, 1921, H. S. Barber, collector.

\section{COENOMYIA FERRUGINEA Scopoli}

Plate 2

Habits.-Larvae appear to be predacious. They have been recorded as occurring in fields and probably feed on white grubs which are common there.

There are no specimens of the larva of this species in the national collection.

Pupa (fig. 12).-Robust, dark yellowish red, the thorax shining, smooth, and the abdomen more yellowish subpolitus, rugose and cylindrical. Head broad, very rugose; antennal capsule deep red, short, robust, annulated on apical portion; in front of the base of each antennal capsule is a short conical process pointing outward; seen from above there is a small, well defined groove medianly in the anterior part of the head, and a long bristle on each side of this groove; below each antenna is a flattened, pointed process pointing outward, and at its base is a stout bristle; in the middle of the dorsal part of the head is a small rugose area with a large bristle on each side, and in the middle of the ventral part of the head is a broad, flattened process extending forward; behind this process is a raised, rugose area; width across head about four times the height. Thorax usually as broad as long, sometimes a little longer than broad; the suture at the anterior edge is very sinuous with a deep notch in the middle; near this notch are two short and one long transverse rugosities; at about the anterior fourth of the dorsum is a transverse sinuous row of small rounded punctures, and on the posterior half of the thorax there are several short, transverse lines of faint punctures; thoracic spiracle (fig. $w$ ) is located dorso-laterally on a prominent elevation; the peritreme is shining deep red while the inner part is luteous and nearly dull; in the skin belonging to the elevation and posterior to the spiracle is a depression with a narrow black line in the middle, and this line is bifureated at the anterior end; near each posterior angle of the thorax is a rounded, well defined depression. Abdomen has eight well defined segments of nearly equal length; first segment without a transverse row of spines at its posterior margin; segments from 2 to 7 with a row of reddish spines posteriorly; segments from 1 to 7 have one central and two dorso-lateral pairs of long yellowish bristles; segments $1,2,6$, and 7 each with a single transverse curved row of small, rounded punctures; segments 3 to 5 each has a double row of such punctures; on a prominent elevation on the side of each segment from 1 to 7 is a heavily chitinized spiracle 
(fig. $x$ ) ; these spiracles are similar to the thoracic spiracles (fig. $w$ ) but are slightly smaller; last segment terminates in two very robust, conical tubercles; near their dorsal base is a median unpaired, deep, rounded puncture; on the dorsum of the segment is a pair of oblique, elliptical depression, the edges of which are faintly annulated on the outer side but quite broad and nearly smooth on the inner side; each side of the segment forms a large, rounded lobe beset with an arcuate row of seven very large, spine-like projections pointing backward; at the basal margin of the segment and near its longitudinal middle line are four spines in a row, the two in the middle very long and the two exterior small. On the venter along the posterior margins of the segments are rows of spines as on the dorsum, but the ventral spines are longer than the dorsal.

Length, $30 \mathrm{~mm}$.; diameter of thorax, $7 \mathrm{~mm}$.; diameter of abdomen, $6 \mathrm{~mm}$.

Fairbury, Ill., no date, A. H. Mundt, collector. Also a small label bearing "22." Another specimen labeled " 3893. Issued April 20, '86."

\section{LEPTIS MYSTACEA Macquart}

\section{Plate 3}

Habits.-Larvae are predacious and have been recorded as occurring under moist dead leaves on the ground in the woods.

There are no specimens of the larvae of this species in the national collection.

Pupa (fig. 13).--Medium sized, luteous, subpolitus; thorax slightly wider than abdomen. Head rounded, slightly wider than high; antennal capsules widely separated, appearing like a long pointed ridge on the front of the head (fig. y); just above and between the bases of the antennae are two round, rugose tubercles; above this pair of tubercles are three faint ocellar punctures; dorsally, at the base of the head, are six radiating faint wrinkles. Thorax slightly longer than wide; on the anterior suture of thorax and close to the median line are two crescent-shaped areas the edges of which are darkened; at each of the anterior thoracic angles is a dark brown, rugose elevation upon which is situated the thoracic spiracle (fig. z) ; its large entrance is yellow and contains numerous small, parallel, eliptical slits; wing pads smooth, reaching to the base of the first segment; leg capsules reaching a little beyond the wing pads. Abdomen is composed of eight segments of equal length; the first segment is smooth and destitute of spines; each of the segments from 2 to 7 has a posterior, transverse row of sharppointed spines of unequal length, and also on the dorso-anterior surface a transverse row of four sharp-pointed spines, of which 
the inner ones are much larger and the outer ones sometimes entirely wanting; on the side of each segment is a broad elevated surface of the length of the segment; on this elevation are two large pointed spines, and sometimes several very small ones, forming a row, and at the anterior portion of the elevation is a small, reddish, elliptical tubercle upon which is located the abdominal spiracle (fig. $a a$ ); the spiracular entrance and general color as in the thoracic spiracle (fig. z); last segment is much narrower than the rest, with a pair of large, black, shining, pointed, conical projections widely separated and black at the tip only; dorsally, between these two pairs of conical projections, is a rounded, well-defined depression.

Length, $12 \mathrm{~mm}$.; diameter of thorax, $2.9 \mathrm{~mm}$; diameter of abdomen, $2.5 \mathrm{~mm}$.

Falls Church, Va., April 19, 1919, in frass at the base of an old decayed tree stump. Reared April 25, 1919, C. T. Greene, collector. Great Falls, Va., April 12, 1924, in a rotten log of sycamore. Reared April 22, 1924, C. T. Greene, collector.

CHRYSOPILA QUADRATA Say

Plate 3

Pupa (fig. 14).-Medium sized, subpolitus, yellowish red; thorax very slightly wider than the abdomen. Head nearly round; antennal capsules very small, pointed at apex, lying quite close to the under side of the head, appearing like small ridges; above the antennae, on the front of the head, are two small, rounded tubercles, and just back of this pair are four small, similar ones in a transverse row; on top of the head are two small bristles widely separated. Thorax about as broad as long; at the anterior median part, along the suture, are two small, pear-shaped rugose areas, each having two small bristles; laterally of these areas, on the anterior angle, is a prominent rugose tubercle upon which is situated the thoracic spiracle (fig. $b b$ ); this spiracle is very small, shining, reddish yellow with a sinuous entrance composed of small radiating, paired slits; on dorsum, near the middle, are two pairs of short bristles, the bristles of the posterior pair closer together; a narrow transverse plate is present at the posterior end of thorax; it is rugose in the middle and at each end of this rugosity are two short bristles; at each anterior angle is a single bristle. Abdomen is composed of eight segments of nearly equal length; each of the segments from 1 to 7 has a narrow transverse ridge near the basal edge; segment 1 has three bristles on each side of the dorsum; segments from 2 to 7 have a transverse, apical row of short, stout spines with a few longer than the majority; segments 1 to 7 have on the side near the basal angle a small rounded tubercle upon which is located a very small 
spiracle (fig. $c c$ ), color and general details as in the thoracic spiracle (fig. bb); last segment has four large pointed processes along the posterior edge with much shorter ones between; the end of the segment is depressed in the middle with four small, rounded tubercles on the edge; ventro-posteriorly the segment is divided into two sharp, pointed, conical appendages.

Length, $10 \mathrm{~mm}$; diameter of thorax, $2 \mathrm{~mm}$; diameter of abdomen, $1.75 \mathrm{~mm}$.

Dead Run, Va. In frass at the base of a tree. Reared May 11, 116, by C. T. Greene, collector.

CHRYSOPILA FASCIATA Say

Plate 3

Pupa (fig. 15).-Small, dull, yellowish red with the thorax subpolitus. Head broader than high; antennal capsules small, narrow, slightly raised on the lower front part of the head; between these capsules are two narrow punctures; below each antenna is a small bristle; above the antennae are two small tubercles close together; just above these are four rounded tubercles in a transverse row, each outer tubercle has a bristle at the apex; above these is another row of four tubercles, the two middle ones much smaller than the two outer ones and each tubercle having a bristle at the apex; on the dorsum near the back of the head is a pair of rounded tubercles widely separated, and just in front of the suture at the back of the head, near the thoracic spiracle, is a small, rounded tubercle; between these tubercles are several radiating rugosities near the middle. Thorax nearly one and one-half times longer than wide; on the middle of the dorsum are four small, rounded tubercles each with a bristle at the apex; on the anterior suture and narrowly separated are two broad, slightly raised, rugose elevations, each having a small bristle at the apex; at each anterior angle is a well defined, elongate tubercle, upon which is located the thoracic spiracle (fig. $d d$ ); this tubercle is reddish yellow, darker at the base; the slit is long, sinuous, yellow, and composed of small, parallel slits; on the side of the thorax, near the middle transverse line and close to the margin, is a single bristle; the narrow plate at the base of the thorax has two bristles on each side widely separated from the corresponding bristles on the opposite side. Abdomen is composed of eight segments, the first seven are nearly equal in length; first segment has a pair of widely separated bristles in the middle of the posterior portion of the dorsum; on each side of this pair are two rather closely set bristles; segments from 2 to 7 have at the posterior third a transverse dorsal row of sharp spines which terminate in a 
short bristle, and near their basal margin have a transverse narrow ridge; each of the segments from 1 to 7 has a small tubercle at about the basal third of the lateral margin on which is located an abdominal spiracle (fig. ee); these spiracles are very similar to the thoracic (fig. $d d$ ) but smaller; last segment about half as long as broad; on the dorsum on each side of the longitudinal middle line are three spines close together, the middle one much the longer; and exterior to these is one large spine with a small one at its base; viewed from behind, in the middle of the segment, is a depression with two rounded tubercles on the upper edge, and on the ventral part of the segment are two conical projections terminating in a sharp point; on the ventral side of the segments from 1 to 7 are rows of spines like those on the dorsum.

Length, $7 \mathrm{~mm}$.; diameter of thorax, $1.85 \mathrm{~mm}$.; diameter of abdomen, $1.25 \mathrm{~mm}$.

Baton Rouge, La., January 1, 1923. Reared April 2, 1923, T. H. Jones and W. G. Bradley, collectors; also labeled "La. Agr. Exp. Sta. No. 1014."

CHRYSOPILA FOEDA Loew

Plate 3

Pupa (fig. 16).-Fairly large, brick red; thorax shining, slightly wider than the abdomen; abdomen cylindrical. Head rounded, slightly depressed in front; antennal capsules small; tapering to a point, closely attached to the head below; on dorsum of head, widely separated, are two small tubercles, each with a bristle on top at the apex. Thorax about as wide as long; along the medianly dorsoanterior suture are two pyriform raised surfaces, each with a small bristle-bearing tubercle; near the anterior angle is a large rugose tubercle, upon which is located the thoracic spiracle (fig. $f f^{\prime}$; the large sinuous entrance place contains a series of small, mostly parallel yellowish slits; in the middle of the dorsum is a pair of short yellow bristles; the small plate at the dorso-basal part of the thorax has a bristle at each anterior angle. Abdomen has eight faintly rugose segments of nearly equal size; first segment, on the posterior half of the dorsum, has six bristles in a transverse row; segments from 2 to 7 have a transverse posterior row of short, closely set spines; segments from 1 to 7 have a tubercle on the sides at about the anterior third and upon the tubercle is located a spiracle (fig. $g g)$; these spiracles are like figure $f ;$, but smaller and not quite so rugose; last segment has a median transverse row of large, pointed, spine-like projections on each side; from the middle outward they are arranged as 3,1 , and 1 ; viewed from the rear the posterior end of the caudal segment is concave medianly with four rounded 
tubercles at the edge; below this concavity are two oblique grooves; the ventral part of the segment terminates in a very large bifid tubercle with each prong pointed at the end; on the ventral side of segments from 1 to 7 are transverse rows of spines similar to the dorsal rows and continuous with these.

Length, $15 \mathrm{~mm}$.; diameter of thorax, $3 \mathrm{~mm}$; diameter of abdomen, $2.70 \mathrm{~mm}$.

Northern Illinois, no date. Collection of D. W. Coquillett.

CHRYSOPILA ORNATA Say

Plate 3

Pupa (fig. 17).-Large, dull, cylindrical, brick red, slightly darker toward caudal end; thorax slightly wider than abdomen. Head much broader than high; on the front part of the head are two pairs of rugose bristle-bearing tubercles, the anterior pair smaller and closer together; below these tubercules, very widely separated, are the antennal capsules, which are rounded, elongate, tapering to a point and fitting close to the head; on the postero-dorsal portion of the head are two widely separated rugose tubercles without bristles. Thorax about as wide as long; along the dorso-anterior suture are two elliptical areas, each area with a median rugose tubercle which terminates in a thin hair; each antero-lateral angle with a prominent rugose tubercle which bears the thoracic spiracle (fig. $h h$ ); the spiracular entrance place is sinuous and composed of numerous, mostly parallel, yellow slits; at the postero-dorsal end of the thorax is a plate which is rugose medianly, each antero-lateral angle has a small bristle-bearing tubercle, and near the anterior edge a transverse row of four bristles; wing pads smooth, reaching to posterior edge of first abdominal segment; leg capsules between and extending slightly beyond the wing pads. Abdomen with eight faintly rugose segments; first segment with a posterior transverse row of three pairs of bristles; segments 2 to 7 with a transverse, posterior row of short spines and three pairs of longer spines in the same row; on the side of each abdominal segment is a prominent faintly rugose tubercle upon which is located a spiracle (fig. $i i)$, details as in figure $h h$, but it is smaller; the last segment has six conical, dorsal lobes each terminating in a thickened, elongated, conical process with a sharp point, the outer one of the lobes generally a little larger than the others; the postero-ventral part of last segment terminates in a broad bifid lobe wih each of the branches pointed at the end; seen irom the rear, the last segment has a deep depression, on the upper and lower edge of which is a pair of prominent tubercles, the upper pair being the larger; below this depression are two well-defined, oblique grooves, pointing downward and outward. 
Length, $16 \mathrm{~mm}$.; diameter of thorax, $3.75 \mathrm{~mm}$; d diameter of abdomen, $3 \mathrm{~mm}$.

Specimen bearing two labels: "Johnson, Pa., April 27, 1900. Issued May 31, 1900," and "9199. In soil."

\section{EXPLANATION OF PLATES}

(Reproduced from drawings by the author)

Plate 1

Fig. 1.-Xylomyia pallipes Loew, larva: $(a)$ anterior spiracle; $(b)$ posterior spiracle. Pupa: $(c)$ anterior thoracic spiracle; $(d)$ abdominal spiracle.

2.-Rhachicerus nitidus Johnson, larva: (e) anterior spiracle; $(f)$ posterior spiracle.

3.-Xylophagus lugens Loew, larva: $(g)$ anterior spiracle; $(h)$ posterior spiracle.

4.-Xylophagus abdominalis Loew, larva: $(i)$ anterior spiracle; $(j)$ posterior spiracle.

5.-Atherix variegata Walker, larva: ( $k$ ) ventral view of proleg.

6.-Vermileo comstockii Wheeler, larval head capsule.

7.-Chrysopila, species, larva: $(f p h)$ frontal portion of head (left half shown $) ;(l)$ head enlarged; $(m)$ anterior spiracle; $(m d)$ mandible; $(n)$ posterior spiracle; $(p l)$ keel-shaped plate.

\section{Plate 2}

FIG. 8.-Xylophagus abdominalis Loew, pupa: $(o)$ anterior thoracic spiracle; ( $p$ ) abdominal spiracle.

9.-Xylophagus lugens Loew, pupa: $(q)$ anterior thoracic spiracle; $(r)$ abdominal spiracle.

10.-Rhachicerus nitidus Johnson, pupa: $(s)$ anterior thoracic spiracle; $(t)$ abdominal spiracle.

11.-Vermileo comstockii Wheeler, pupa: $(u)$ anterior thoracic spiracle; $(v)$ abdominal spiracle.

12.-Coenomyia ferruginea Scopoli, pupa: $(w)$ anterior thoracic spiracle; $(x)$ abdominal spiracle.

Plate 3

Fig. 13.-Leptis mystacea Macquart, pupa: $(y)$ ventral view of head; $(z)$ an terior thoracic spiracle; $(a a)$ abdominal spiracle.

14.-Chrysopila quadrata Say, $(b b)$ anterior thoracic spiracle; $(c c)$ abdominal spiracle.

15.-Chrysopila fasciata Say, (dd) anterior thoracic spiracle; (ee) abdominal spiracle.

16.-Chrysopila foeda Loew, ( $f f)$ anterior thoracic spiracle; ( $g g$ ) abdominal spiracle.

17.-Chrysopila ornata Say, ( $h h$ ) anterior thoracic spiracle; (ii) abdominal spiracle. 


\section{$2 \mathrm{BHL}$ Biodiversity Heritage Library}

Greene, Charles T. 1926. "Descriptions of larvae and pupae of two-winged flies belonging to the family Leptidae." Proceedings of the United States National Museum 70(2651), 1-20. https://doi.org/10.5479/si.00963801.70-2651.1.

View This Item Online: $\underline{\text { https://www.biodiversitylibrary.org/item/53444 }}$ DOI: https://doi.org/10.5479/si.00963801.70-2651.1

Permalink: https://www.biodiversitylibrary.org/partpdf/52001

\section{Holding Institution}

Smithsonian Libraries

\section{Sponsored by}

Smithsonian

\section{Copyright \& Reuse}

Copyright Status: Public domain. The BHL considers that this work is no longer under copyright protection.

This document was created from content at the Biodiversity Heritage Library, the world's largest open access digital library for biodiversity literature and archives. Visit BHL at https://www.biodiversitylibrary.org. 